\title{
Posttranslational Modifications of Tubulin and Cilia
}

\author{
Dorota Wloga, ${ }^{1}$ Ewa Joachimiak, ${ }^{1}$ Panagiota Louka, ${ }^{2}$ and Jacek Gaertig ${ }^{2}$ \\ ${ }^{1}$ Laboratory of Cytoskeleton and Cilia Biology, Department of Cell Biology, Nencki Institute \\ of Experimental Biology, Polish Academy of Sciences, 02-093 Warsaw, Poland \\ ${ }^{2}$ Department of Cellular Biology, University of Georgia, Athens, Georgia 30602 \\ Correspondence: dwloga@nencki.gov.pl; jgaertig@uga.edu
}

Tubulin undergoes several highly conserved posttranslational modifications (PTMs) including acetylation, detyrosination, glutamylation, and glycylation. These PTMs accumulate on a subset of microtubules that are long-lived, including those in the basal bodies and axonemes. Tubulin PTMs are distributed nonuniformly. In the outer doublet microtubules of the axoneme, the B-tubules are highly enriched in the detyrosinated, polyglutamylated, and polyglycylated tubulin, whereas the A-tubules contain mostly unmodified tubulin. The nonuniform patterns of tubulin PTMs may functionalize microtubules in a position-dependent manner. Recent studies indicate that tubulin PTMs contribute to the assembly, disassembly, maintenance, and motility of cilia. In particular, tubulin glutamylation has emerged as a key PTM that affects ciliary motility through regulation of axonemal dynein arms and controls the stability and length of the axoneme.

\section{TYPES OF CONSERVED TUBULIN PTMs}

Tubulin undergoes several conserved posttranslational modifications (PTMs) (Janke 2014; Song and Brady 2015; Yu et al. 2015). The most studied tubulin PTMs and their responsible enzymes are summarized in Figure 1. These PTMs are enriched on the long-lived microtubules, including those of cilia and centrioles. Some tubulin PTMs appear to have coevolved with cilia (Janke et al. 2005; Shida et al. 2010). Although antibodies that recognize PTMs have been widely used to detect cilia (Magiera and Janke 2013), the functions of tubulin PTMs have started to emerge only recently. Within the cilium, there are striking differences in the levels of tubulin PTM among the specific microtu- bules and along the length or even around the circumference of the same microtubule (Fig. 2). According to the "tubulin code" model (Verhey and Gaertig 2007), tubulin PTMs form patterns of marks on the microtubules that locally influence various activities, such as the motility of motor proteins or severing factors. Although we focus on cilia, we will discuss key findings on the nonciliary microtubules as well, as it is likely that tubulin PTMs provide related if not identical functions inside and outside of cilia.

\section{ACETYLATION OF K40 OF $\alpha$-TUBULIN}

This highly conserved PTM was discovered in cilia of Chlamydomonas reinhardtii (L'Hernault

Editors: Wallace Marshall and Renata Basto

Additional Perspectives on Cilia available at www.cshperspectives.org

Copyright (C) 2017 Cold Spring Harbor Laboratory Press; all rights reserved; doi: 10.1101/cshperspect.a028159

Cite this article as Cold Spring Harb Perspect Biol 2017;9:a028159 
D. Wloga et al.

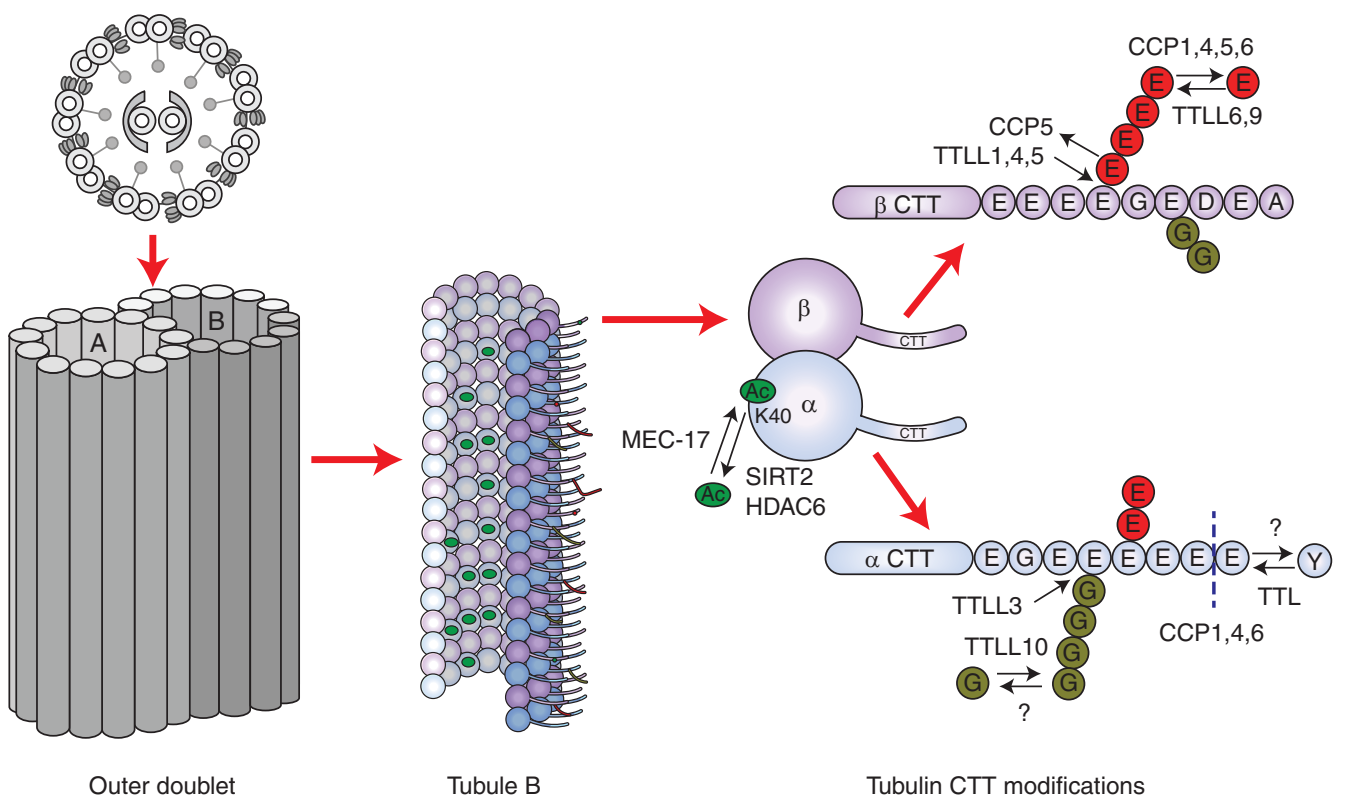

Figure 1. Conserved and widely studied types of tubulin posttranslational modifications (PTMs) and the responsible enzymes that act in cilia. CTT, Carboxy-terminal tail; TTL(L), tubulin tyrosine ligase(-like); CCP, cytosolic carboxypeptidase.

and Rosenbaum 1983; LeDizet and Piperno 1987). Acetyl-K40 is the only known PTM that is located inside the microtubule lumen (Nogales et al. 1999; Soppina et al. 2012). Although mass spectrometry detected additional acetylKs on tubulin (Choudhary et al. 2009; Chu et al. 2011; Liu et al. 2015), acetyl-K40 is the most abundant, if not exclusive in cilia (Akella et al. 2010). Acetyl-K40 marks long-lived microtubules, including those in the axonemes and basal bodies (Piperno and Fuller 1985). The enzyme that generates acetyl-K40, MEC-17/ATAT1 (Akella et al. 2010; Shida et al. 2010), has a catalytic domain homologous to that of the histone acetyltransferases (Friedmann et al. 2012; Kormendi et al. 2012; Li et al. 2012; Taschner et al. 2012; Davenport et al. 2014; Yuzawa et al. 2015), but its enzymatic rate is relatively slow because of "suboptimal" positions of the catalytic residues. Consequently, only long-lived microtubules carry acetyl-K40 (Szyk et al. 2014). Most of the axonemal $\alpha$-tubulin has acetyl-K40 (Gaertig et al. 1995), and the PTM is present on both the central and outer microtubules (Piperno and Fuller 1985; Satish Tammana et al. 2013).
Tetrahymena mutants lacking MEC-17/ ATAT1 or expressing a K40R nonacetylatable $\alpha$-tubulin have a normal gross phenotype but display altered sensitivities to tubulin-binding compounds (Gaertig et al. 1995; Akella et al. 2010). In Chlamydomonas, expression of a K40R $\alpha$-tubulin did not detectably affect the gross phenotype (Kozminski et al. 1993). Surprisingly, in the apicomplexan Toxoplasma gondii, K40R $\alpha$-tubulin-expressing parasites are viable only if a second mutation that confers oryzalin resistance (and likely changes the dynamics of microtubules) is cointroduced into $\alpha$-tubulin. Furthermore, a depletion of MEC17/ATAT1 in Toxoplasma inhibits mitosis and changes cell shape, indicating that the lack of acetylation affects both the nuclear and subpellicular microtubules (Varberg et al. 2016). In Caenorhabditis elegans, the acetyl-K40 $\alpha$-tubulin is expressed exclusively in the mechanosensory (ciliated and nonciliated) neurons (Fukushige et al. 1999; Shida et al. 2010). Without MEC-17/ATAT1, the animals become touch-insensitive (Chalfie and Au 1989; Zhang et al. 2002; Akella et al. 2010; Shida et al. 2010), and 

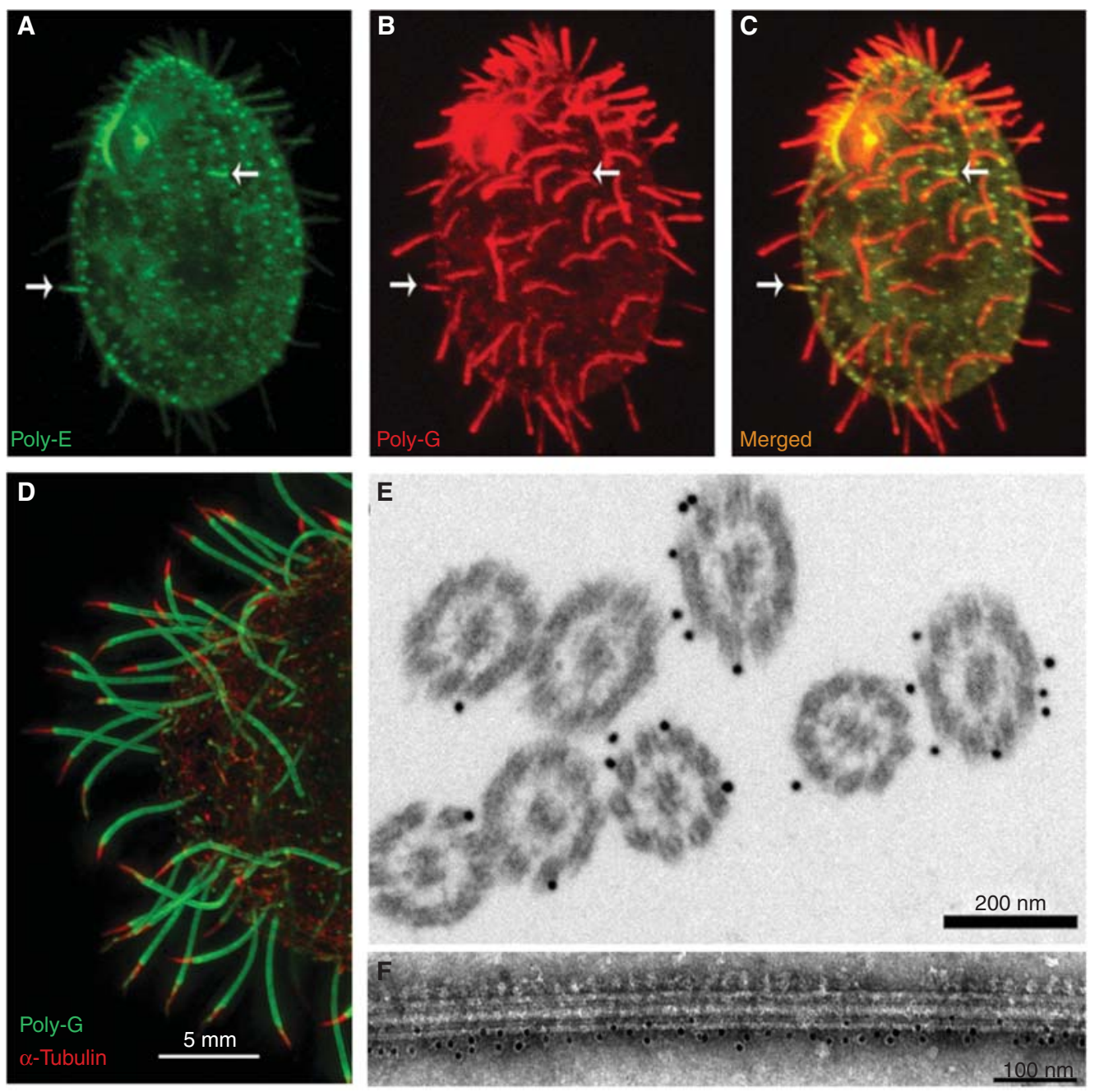

Figure 2. The nonuniform patterns of tubulin PTMs in cilia. (A-C) A Tetrahymena cell labeled with antibodies that recognize either polyglutamate (poly-E, green) (Shang et al. 2002) or polyglycine side chains (AXO49) (Bré et al. 1998). Note that the shorter assembling cilia (arrows) have a higher signal of polyglutamylation and a lower signal of polyglycylation as compared to the longer mature cilia on the same cell. These data suggest that during their assembly, cilia undergo remodeling of tubulin PTMs. (Figure adapted from Sharma et al. 2007; originally published in Journal of Cell Biology.) (D) A superresolution structured illumination microscopy (SR-SIM) image of the posterior end of a Tetrahymena cell, with cilia labeled with poly-G (green) (Duan and Gorovsky 2002) and anti- $\alpha$-tubulin primary sequence antibodies 12G10 (red) (Jerka-Dziadosz et al. 1995). Note an absence of a signal of poly-G near the tips of cilia (distal segment) where the B-tubules are absent. (E) A postembedding immunogold image of cross sections of Tetrahymena cilia labeled with antipolyglycine AXO49 antibodies. Note the absence of a signal near the central microtubules. (From Wloga et al. 2009; adapted, with permission.) $(F)$ An isolated doublet microtubule of Chlamydomonas labeled by poly-E antibodies with $10 \mathrm{~nm}$ colloidal gold and negatively stained with uranyl acetate. The A-tubule side can be identified by the presence of dynein arms (top), whereas the B-tubule has a smoother surface (bottom). Note that the gold particles are enriched along the Btubule. (From Kubo et al. 2010; reprinted, with permission, from Elsevier (C) 2010.) 
D. Wloga et al.

the neurites of the nonciliated touch receptor neurons contain fewer microtubules that have reduced diameters and lattice defects and are prone to buckling as the animal body bends (Cueva et al. 2012; Topalidou et al. 2012). A molecular dynamics simulation suggests that acetylation of K40 promotes the cohesion between protofilaments of microtubules (Cueva et al. 2012). Thus, it appears that acetyl-K40 has a microtubule lattice-stabilizing activity. Importantly, MEC-17/ATAT1 has additional functions beyond its acetyltransferase activity. The loss of touch sensation in the C. elegans mec-17 mutant animals (but not the defects in microtubule organization) can be rescued by expression of a catalytically inactive MEC17/ATAT1 (Topalidou et al. 2012). Also, the mammalian MEC-17/ATAT1 has a microtubule-destabilizing activity that is independent of its acetyltransferase activity (Kalebic et al. 2013a,b). Although siRNA depletion of MEC-17/ATAT1 delays the assembly of primary cilia (Shida et al. 2010), the mice lacking MEC-17/ATAT1 have not been reported to have cilia that are structurally defective or of improper length (Kalebic et al. 2013b; Kim et al. 2013).

\section{ROLE OF ACETYL-K40 AND ASSOCIATED ENZYMES IN THE DISASSEMBLY OF CILIA}

HDAC6 (Hubbert et al. 2003; Zhang et al. 2003) and SIRT2 (North et al. 2003) are two acetylK40 deacetylases that promote disassembly of primary cilia in mammalian cells. Knockdowns of either HDAC6 or SIRT2 increase the frequency of primary cilia or make them longer, whereas overexpressions lead to fewer or shorter cilia (Pugacheva et al. 2007; Yang et al. 2014; Zhou et al. 2014; Bangs et al. 2015; Ran et al. 2015). The cilia-shortening effect of overexpressed HDAC6 is counteracted by overexpression of a K40Q (acetyl-K mimic) $\alpha$-tubulin indicating that HDAC6 acts through deacetylation of acetyl-K40. Thus, by deacetylating acetyl-K40, HDAC6 and SIRT2 could have a microtubule lattice-destabilizing effect (Cueva et al. 2012). Alternatively, deacetylation could enable another PTM on K40. In Chlamydomonas, $\alpha$-tubulin (but not $\beta$-tubulin) undergoes lysine poly- ubiquitination when the cilium disassembles (Huang et al. 2009). However, the effects of HDAC6 and SIRT2 are unlikely to be mediated solely by K40 ubiquitination, because polyubiquitinated $\alpha$-tubulin has acetyl-K40 (Huang et al. 2009). HDAC6 also deacetylates cortactin, and this activity also shortens the cilium, by promoting actin polymerization around the base of the primary cilium (Ran et al. 2015); it is well documented that actin dynamics affects the length of cilia (discussed in Liang et al. 2016). The HDAC6 knockout mouse lacks ciliary phenotypes (Zhang et al. 2008), but the loss of HDAC6 could be covered by SIRT2.

\section{ROLE OF ACETYL-K40 IN MOTOR-DRIVEN MOTILITY}

Acetyl-K40 may influence motor proteins, also in cilia. Mice lacking MEC-17/ATAT1 are healthy, but the males have defective sperm cells whose flagella beat with a reduced bend amplitude (Kalebic et al. 2013b; Kim et al. 2013). Enzymatic acetylation of K40 increases, whereas deacetylation by SIRT2 decreases the rate of motility of axonemal outer arm dynein on microtubules in vitro, respectively (Alper et al. 2014). The effect of acetyl-K40 on the motility of axonemal dynein is surprising because $\mathrm{K} 40$ is located inside the microtubule lumen (Nogales et al. 1999; Soppina et al. 2012). However, changes in the microtubule lumen can affect the functionality of the external surface (Raff et al. 2008). Cryoelectron tomography failed to detect a difference between the tubulin dimers inside microtubules that are assembled of either acetylated or nonacetylated tubulin, but perhaps the resolution achieved ( $8 \AA$ ) was insufficient to detect a change that affects dynein (Howes et al. 2014).

In vitro, kinesin-1 binds more weakly and moves more slowly on mutant axonemes containing K40R $\alpha$-tubulin, as compared to wildtype axonemes carrying acetyl-K40 (Reed et al. 2006). However, more recent studies that used enzymatically in vitro acetylated or deacetylated microtubules failed to detect an effect of acetylK40 on kinesin-1 motility in vitro (Walter et al. 2012; Kaul et al. 2014). In the study that reported a positive result for kinesin-1 (Reed et al. 
2006), the nonacetylated microtubules were produced genetically and used in the form of isolated axonemes. The K40R mutation could have altered the composition of other axonemal proteins or the levels of other tubulin PTMs. One potential "reader" of the acetyl-K40 mark is a protein with a bromodomain, found in the flagellum of Trypanosoma (Alonso et al. 2014). Also, acetyl-K40 could affect the components of the lumen of outer doublets, microtubule inner proteins (MIPs) (Nicastro et al. 2011; Yanagisawa et al. 2014). Although the effects of acetylK40 on other tubulin PTMs have not been studied, a reverse relationship exists: The levels of acetyl-K40 increase in the axonemes of Tetrahymena mutants that are deficient in tubulin glycylation (Wloga et al. 2009). Such a PTM cross talk could compensate for an absence of acetyl-K40 and could explain the mild consequences of the loss of this PTM in some models.

\section{DETYROSINATION OF $\alpha$-TUBULIN}

The carboxy-terminal $\mathrm{Y}$ on $\alpha$-tubulin is removed by an unidentified carboxypeptidase resulting in detyrosination that occurs preferentially on microtubules (Kumar and Flavin 1981; Arce and Barra 1983). The tubulin tyrosine ligase (TTL) restores the carboxy-terminal Y on the unpolymerized tubulin (Schroder et al. 1985; Ersfeld et al. 1993; Szyk et al. 2011; Prota et al. 2013). Mice lacking TTL die shortly after birth, with defects in the organization of neurons (Erck et al. 2005). In cilia, detyrosinated tubulin is enriched on the B-tubules of outer doublets (Johnson 1998). The anterograde intraflagellar transport (IFT) trains that are driven by kinesin-2 move on the B-tubule, whereas the retrograde trains driven by IFT dynein move on the A-tubule (Kozminski et al. 1995; Pigino et al. 2009; Stepanek and Pigino 2016). In vitro, detyrosination increases the velocity and processivity of kinesin-2, suggesting that this PTM could stimulate the anterograde IFT (Sirajuddin et al. 2014). Detyrosination increases the landing rate of kinesin-1 on microtubules (Kaul et al. 2014). A combination of effects on the landing rate and processivity could explain the bias of kinesin-2driven anterograde IFT trains for the B-tubule, which in turn could mediate the collision-free trafficking between the base and the tip of the cilium (Stepanek and Pigino 2016). However, the B-tubule is also modified by polymodifications (see below). How the retrograde IFT trains could be biased for the A-tubule is less clear. The A-tubule has low levels of PTMs and its $\alpha$-tubulin is mostly tyrosinated (Johnson 1998). The yeast cytoplasmic dynein, a motor similar to IFT dynein, is not sensitive to the status of the carboxy-terminal Y (Sirajuddin et al. 2014).

\section{GLUTAMYLATION}

Glutamylation is an addition of a side-chain peptide composed of Es to the $\gamma$-carboxyl group of an $\mathrm{E}$ in the protein primary sequence (Eddé et al. 1990). Glutamylation occurs on multiple E sites within the carboxy-terminal tail domains (CTTs) of $\alpha$ - and $\beta$-tubulin (Redeker et al. 1991, 1992). The CTTs are flexible domains that are likely to form a negatively charged "polymer brush" on the microtubule (Roll-Mecak 2015). A related PTM, tubulin glycylation, occurs within the same cluster of Es (Redeker et al. 1994) and the two polymodifications are in a competition (Rogowski et al. 2009; Wloga et al. 2009). In Tetrahymena, a substitution of multiple Es (to charge-conserving but nonmodifiable Ds) on the CCT of $\beta$-tubulin, causes a failure in the axoneme assembly, including its shortness, loss of the central microtubules, and loss of the B-tubules (Xia et al. 2000; Thazhath et al. 2002). A substitution of all Es on the CTT of $\alpha$-tubulin is well tolerated (Wloga et al. 2008). The exact placement of the modifiable Es on tubulin is not important; for example, the severe axoneme assembly defect caused by $\mathrm{E}$ to $\mathrm{D}$ substitutions on $\beta$-tubulin is rescued by replacement of the CTT of $\alpha$-tubulin with the corresponding sequence of the $\beta$-tubulin CTT (Xia et al. 2000; Duan and Gorovsky 2002).

Glutamylation is generated by a subset of enzymes related to TTL, TTL-like proteins (or TTLLs) (Janke et al. 2005). The glutamylating (glutamylase) TTLLs use a region adjacent to the enzymatic core as a microtubule-binding domain and preferably modify microtubules over unpolymerized tubulin (Garnham et al. 
D. Wloga et al.

2015). There are several glutamylase TTLL subtypes, which differ in the levels of chain-initiating and elongating activities, on either $\alpha$ - or $\beta$ tubulin, but the exact enzymatic profiles vary greatly among the TTLL orthologs or even paralogs (van Dijk et al. 2007; Wloga et al. 2008; Suryavanshi et al. 2010). The catalytic core of the mammalian TTLL7 is flexible enough to allow the microtubule-docked enzyme to perform both chain initiation and elongation reactions on $\beta$-tubulin (Mukai et al. 2009; Garnham et al. 2015), but other TTLLs are active mostly in either initiation or elongation (van Dijk et al. 2007; Wloga et al. 2008; Suryavanshi et al. 2010). Some TTLLs have an autonomous activity, whereas others need associated activators (Janke et al. 2005). TTLLs are enriched in cilia and basal bodies (van Dijk et al. 2007; Wloga et al. 2008; Suryavanshi et al. 2010). In mammalian and zebrafish cells, a centrosomal protein, CEP41, is required for targeting of TTLL6 to cilia (Lee et al. 2012). In Chlamydomonas cilia, TTLL9 is transported by IFT, in a complex with an adapter, FAP234 (Kubo et al. 2014).

Trimming of the polyglutamate side chains on tubulin (deglutamylation) is accomplished by the zinc carboxypeptidases: CCP1, $-4,-5$, and -6 (Kimura et al. 2010; Rogowski et al. 2010; Tort et al. 2014). CCPs also remove the terminal $\mathrm{E}$ from the end of detyrosinated $\alpha$-tubulin, creating the " $\Delta 2 \alpha$-tubulin" (Rogowski et al. 2010) also in cilia (Paturie-Lafanechère et al. 1994). Polyglutamylation also occurs on nontubulin proteins (van Dijk et al. 2008), and the same TTLL can glutamylate both a tubulin and a nontubulin substrate (van Dijk et al. 2007; Xia et al. 2016). CCPs also deglutamylate nontubulin proteins (Rogowski et al. 2010; Ye et al. 2014). Thus, caution is needed in the interpretation of the effects of manipulations of TTLLs or CCPs. In Tetrahymena, glutamylated tubulin is present on the outer doublets but absent from the central pair (Suryavanshi et al. 2010). However, the central microtubules are glutamylated in the sperm of Drosophila melanogaster and Lytechinus pictus (Hoyle et al. 2008). In motile cilia, within the outer doublet, glutamylation is enriched on the B-tubule (Fig. 2F) (Lechtreck and Geimer 2000; Kubo et al. 2010;
Suryavanshi et al. 2010). It is not clear to what extent this enrichment is a result of targeting of TTLLs or CCPs or a consequence of the saturation of most of the A-tubule surface with protein complexes such as dynein arms and radial spokes (Ishikawa 2015).

\section{GLUTAMYLATION AND CILIARY MOTILITY}

Loss of glutamylating TTLL subtypes (TTLL1, TTLL5, TTLL6, TTLL9) either disturbs the waveform or reduces the beat frequency or causes stalling of motile cilia (Ikegami et al. 2010; Kubo et al. 2010; Suryavanshi et al. 2010; Pathak et al. 2011; Bosch Grau et al. 2013; Konno et al. 2016); in most of these studies, the motility defects are not associated with gross structural defects in the axoneme (with some exceptions, see below). In the mouse, loss of function of TTLL1 phenocopies primary ciliary dyskinesia associated with reduced motility of respiratory cilia (Ikegami et al. 2010; Vogel et al. 2010). Among the axonemal dynein arms that drive ciliary motility, the inner dynein arms (IDAs) are mainly involved with the ciliary waveform, whereas the outer dynein arms (ODAs) control the beat frequency (Kamiya 2002). The reduction in the beat frequency in the absence of TTLL6, a $\beta$-tubulin elongase (Suryavanshi et al. 2010; Pathak et al. 2011; Bosch Grau et al. 2013), indicates that glutamylation regulates ODAs. Of key importance is that in Chlamydomonas, a mutant lacking ODAs has residual ciliary motility (supported by the IDAs alone), but a double mutant lacking TTLL9 glutamylase and ODAs is completely paralyzed. This indicates that tubulin glutamylation is essential for the waveform control by IDAs (Kubo et al. 2010). A depletion of CCP5 in zebrafish leads to hyperglutamylation of ciliary microtubules and a reduction in the beat amplitude of pronephric cilia (Pathak et al. 2014). Surprisingly, in vitro, in the axonemes lacking ODAs that were treated with ATP, the velocity of sliding of microtubules increases in the absence of either TTLL9 or TTLL6 (Kubo et al. 2010; Suryavanshi et al. 2010). This leads to a counterintuitive model that the IDA activity on microtubules is inhibited by tubulin glutamylation. There are several subtypes of IDAs, 
each occupying a different position within the 96-nm repeat on the A-tubule (Bui et al. 2009; Barber et al. 2012). In Chlamydomonas, a loss of TTLL9 specifically affects the function of dynein e, an IDA subspecies (Kubo et al. 2012). This effect could involve positive charge patches in the microtubule-biding domain of dynein e that could interact with the negatively charged polyglutamate side chains (Kubo et al. 2012). Glutamylation of tubulin on the B-tubule could increase the time spent by dynein e in a microtubule-bound state. This could increase the cohesion between the adjacent microtubule doublets and affect the engagement of other dyneins with the B-tubule (Kubo et al. 2012). Alternatively, the dynein e/B-tubule links could increase the microtubule curvature by generating a drag force on the microtubules that are simultaneously pushed by other "faster" dyneins (Kotani et al. 2007; Suryavanshi et al. 2010). In addition to the effects on dynein e, TTLL9 also affects the axoneme integrity by influencing the DRC-nexin/B-tubule links between the adjacent doublets (Kubo et al. 2012; Alford et al. 2016).

\section{GLUTAMYLATION IN CILIARY ASSEMBLY AND MICROTUBULE STABILITY}

Glutamylating TTLLs are important for the assembly or stability of ciliary microtubules, most notably in the mammalian sperm. The males of mice lacking TTLL1 or its partner subunit Pgs1 are infertile and produce sperm with truncated axonemes (Campbell et al. 2002; Regnard et al. 2003; Vogel et al. 2010). In the TTLL5-null mouse, the sperm axonemes frequently lack a single doublet, number 4 (Lee et al. 2013). Similarly, a deletion of TTLL9 leads to a loss of the distal portion of doublet 7 in the sperm axoneme (Konno et al. 2016).

The sperm axoneme defects could result from either a lack of proper assembly or instability. In the Tetrahymena cells overproducing TTLL6, the cytoplasmic microtubules undergo hyperglutamylation and excessive stabilization, associated with increased K40-acetylation and resistance to depolymerization (Wloga et al. 2010). Tubulin glutamylation could increase the microtubule stability by promoting the binding of stabilizing factors. Centriole and spindle-associated protein (CSAP) colocalizes with the polyglutamylated microtubules, including those in cilia, centrioles, and the mitotic spindle (Backer et al. 2012). Depletion of CSAP destabilizes microtubules of the mitotic spindle (Ohta et al. 2015). In zebrafish, a depletion of CSAP causes defects in the left-right asymmetry in association with impaired beating of cilia inside Kupffer's vesicle (Backer et al. 2012). Thus, CSAP could be a tubulin code reader that recognizes and stabilizes polyglutamylated microtubules, including those present in motile cilia.

The axoneme structure defects could result from a suboptimal IFT (Hou et al. 2007; Dave et al. 2009). The anterograde IFT trains driven by kinesin-2 move on the B-tubule of the outer doublets (Kozminski et al. 1995; Pigino et al. 2009; Stepanek and Pigino 2016), which is enriched in tubulin glutamylation (Lechtreck and Geimer 2000; Kubo et al. 2010; Suryavanshi et al. 2010). Polyglutamylation of $\beta$-tubulin increases the processivity and speed of kinesin- 2 on microtubules in vitro (Sirajuddin et al. 2014). The velocity of Osm 3 kinesin-2 increases on the hyperglutamylated axonemes in cilia of C. elegans lacking CCP1 (O’Hagan et al. 2011). In zebrafish, defects in ciliogenesis caused by depletions of either fleer/DYF1/IFT70 or IFT88 IFT train subunits are partially rescued by a depletion of CCP5 (Pathak et al. 2014), arguing that increased tubulin glutamylation can improve a suboptimal IFT. However, the axoneme assembly defects caused by deficiencies in TTLLs could also be caused by a lack of glutamylation of nontubulin proteins. In addition to the sperm defects (Lee et al. 2013), a loss of TTLL5 also causes retinal dystrophy (Sergouniotis et al. 2014), but this phenotype is mainly, if not entirely, caused by a lack of glutamylation of RPGR, a protein that functions in the connecting cilium of the photoreceptor (Sun et al. 2016).

\section{ROLE OF GLUTAMYLATION IN THE DISASSEMBLY AND NEGATIVE LENGTH REGULATION OF CILIA}

Excessive tubulin glutamylation may destabilize and shorten cilia. In C. elegans, despite a stim- 
D. Wloga et al.

ulatory effect on the anterograde IFT velocity described above, a loss of CCP1 causes an agedependent degeneration of cilia, including a loss of the B-tubules (O'Hagan et al. 2011). A loss of CCP1 in the $(p c d)$ mouse causes degeneration of the Purkinje neurons, bulb mitral cells, and retina photoreceptors and male sterility (Greer and Shepherd 1982; Fernandez-Gonzalez et al. 2002; Rogowski et al. 2010). Because all of the cell types affected in the $p c d$ mouse are ciliated, these phenotypes can at least in part be caused by a degeneration of cilia. Consistently, the mammalian CCP1 is a positive regulator of the length of the primary cilium (Kim et al. 2010). In Tetrahymena, overexpression of TTLL6 glutamylase causes rapid shortening and fragmentation of axonemes and a loss of B-tubules (Wloga et al. 2010), which phenocopies overexpression of katanin (Sharma et al. 2007). The depolymerizing effect of TTLL6 is axonemespecific; in the same cells, nonciliary microtubules undergo stabilization (Wloga et al. 2010). This argues that hyperglutamylation does not have a microtubule disassembly-promoting effect per se but rather that it activates axoneme-associated microtubule depolymerizers. Specifically, hyperglutamylation could activate katanin to sever the axoneme (O'Hagan and Barr 2012). There is substantial evidence that tubulin glutamylation stimulates katanin and the structurally similar spastin (Lu et al. 2004; Sharma et al. 2007; Roll-Mecak and Vale 2008; Lacroix et al. 2010; Valenstein and Roll-Mecak 2016). Katanin subunits are present inside cilia where they associate with the outer doublets (Dymek et al. 2004; Sharma et al. 2007).

Recent observations in Chlamydomonas provide further evidence that links tubulin glutamylation to axoneme stability and depolymerization and ultimately to the length of the cilium. It has been puzzling that Chlamydomonas mutants that lack repeated components on the A-tubule (IDAs, ODAs, DRC-nexin) often have short cilia (Huang et al. 1979; LeDizet and Piperno 1995; Yamamoto et al. 2010). A loss of function of either TTLL9 or the associated FAP234 reduces tubulin glutamylation in cilia and, surprisingly, partially rescues the length defect of the IDA, ODA, and DRC-nexin mu- tants (Kubo et al. 2015). Thus, tubulin glutamylation has a strong shortening effect on an axoneme that has incomplete A-tubule-associated protein complexes. Importantly, a loss of either FAP234 or TTLL9 alone mildly elongates cilia and decreases the rate of ciliary disassembly (Kubo et al. 2015). In the absence of TTLL9, other TTLLs could provide the IFT-promoting function of tubulin glutamylation (discussed above). It therefore appears that the repeated protein complexes bound to the A-tubule stabilize the axoneme and are in competition with tubulin glutamylation that destabilizes the axoneme. It is tempting to speculate that the shortening of the axoneme is mediated by tubulin glutamylation that activates ciliary katanin.

Surprisingly, a loss of katanin causes shortening of cilia and a failure to assemble the central pair (Dymek et al. 2004; Sharma et al. 2007; Dymek and Smith 2012), a counterintuitive phenotype for a microtubule-severing factor. However, in vitro, the severing activity of another microtubule depolymerizer, spastin, is dependent on the number of glutamates per tubulin, with a small number stimulating spastin and a large number inhibiting spastin (Valenstein and Roll-Mecak 2016). The levels of tubulin polyglutamylation detected by antibodies are higher in the assembling cilia than in the steady-state cilia, which also have a higher level of polyglycylation (Fig. 1A-C) (Adoutte et al. 1991; Sharma et al. 2007; Bosch Grau et al. 2013). It is possible that the polyglutamate side chains undergo remodeling as the cilium matures, including their shortening (by deglutamylases) and replacement by the polyglycine chains (see below). Such a PTM remodeling could modulate the possible multiple activities of katanin at different stages of ciliogenesis.

\section{TUBULIN GLYCYLATION}

Although all ciliated species have tubulin glutamylation (Janke et al. 2005), most, but not all, have tubulin glycylation (Adoutte et al. 1985; Bré et al. 1996). Glycylation is generated by a subset of TTLLs: TTLL3 is an initiase (Rogowski et al. 2009; Wloga et al. 2009), whereas TTLL10 is an elongase (Ikegami et al. 2008; Ikegami and 
Setou 2009; Rogowski et al. 2009). One exception is D. melanogaster in which polyglycylated tubulin is generated by TTLL3 alone (Rogowski et al. 2009). Curiously, in the ciliated cells of primates (including humans), the side chain is limited to a single G (monoglycylation), because of a mutation that inactivates the catalytic center of TTLL10 (Kann et al. 1998; Million et al. 1999; Rogowski et al. 2009). Tetrahymena cells with a knockout of all six paralogs of TTLL3 grow poorly and have slightly shorter, but ultrastructurally normal cilia that, unlike wild-type cilia, fail to elongate in the presence of paclitaxel, indicating a subtle defect in the tubulin turnover in the axoneme (Wloga et al. 2009). In zebrafish, a morpholino knockdown of TTLL3 glycylase causes reversals in the direction of ciliary beating in the pronephron. A depletion of TTLL6 glutamylase reduces the beat frequency (Pathak et al. 2011). Surprisingly, a depletion of both TTLL3 and TTLL6 leads to high penetrance ciliary phenotypes, including the body axis curvature and pronephric cysts, associated with reduced ciliary beat amplitude and even paralysis of pronephric cilia (Pathak et al. 2011). The axonemes depleted in both TTLL3 and TTLL6 often lack the B-tubules and have misplaced doublets and ectopic central singlets (Pathak et al. 2011). The severe assembly defects in the zebrafish depleted in TTLL3 and TTLL6 are reminiscent of the profound failure in the assembly of the axoneme in Tetrahymena mutants with substitutions in the modifiable Es on the CTT of $\beta$-tubulin (Xia et al. 2000; Thazhath et al. 2002). Thus, tubulin glycylation and glutamylation could both compete and cooperate in providing essential functions for axoneme assembly and motility. Polyglycine side chains are predicted to have an extended conformation, whereas the polyglutamate side chains may form swollen coils because of increased charge repulsion (Roll-Mecak 2015), supporting a view that the two polymodifications have different biological effects. In the mouse and Drosophila, tubulin glycylation could be important on its own. In Drosophila, a depletion of TTLL3 with RNAi causes male sterility associated with a failure in the axoneme assembly (Rogowski et al. 2009). In the murine ependy- mal cells, a depletion of TTLL3 destabilizes already assembled motile cilia (Bosch Grau et al. 2013) and reduces the frequency of primary cilia in the colon epithelium (Rocha et al. 2014). Because a loss of glycylation leads to an increase in glutamylation (Rogowski et al. 2009; Wloga et al. 2009), it will be of interest to address whether, in the mouse, the defects in cilia caused by depletions of TTLL 3 are mediated by tubulin hyperglutamylation.

\section{CONCLUSION}

It is increasingly convincing that tubulin PTMs play multiple important roles in cilia. The tubulin code model, originally inspired by the studies on histone tail modifications, seems useful in exploring the functions of microtubule PTMs. Many microtubule interactors, such as the motors, +TIPs, and even the tubulin code generators themselves (MEC-17/ATAT1 [Szyk et al. 2014] and TTLL7 [Garnham et al. 2015]) either walk unidirectionally or undergo a one-dimensional diffusion along the microtubule surface or inside its lumen. Thus, microtubule interactors can sense and respond to the PTM marks in a processive manner and therefore can be seen as genuine readers of the tubulin code. Inside the axoneme, the nonuniform patterns of PTM marks (Fig. 2) may be critical for the confinement of the anterograde and retrograde IFT streams to separate tubules of the outer doublets, and for the generation of the bend curvature in motile cilia. Although the evidence behind the importance of the tubulin code is growing steadily, a major challenge is in linking the phenotypes produced by manipulations of tubulin PTM enzymes to tubulin modifications. This task is difficult because of the complexity of the PTM pathways, which include nontubulin modification targets and nonenzymatic activities of the tubulin PTM enzymes. Despite these challenges, exploring the cilium has proved productive in generating ideas about the mechanisms and the biological effects of the tubulin code. The same studies have greatly added to the knowledge about how cilia assemble, maintain their length, and move. 
D. Wloga et al.

\section{ACKNOWLEDGMENTS}

The work in the laboratory of D.W. is currently supported by funds from the National Science Center (Harmonia 6, 2014/14/M/NZ3/00511) and the European Molecular Biology Organization (EMBO) (IG No. 2331). E.J. is supported by a Polish Ministry of Science and Higher Education Grant (N N303 817840). Work in the laboratory of J.G. is supported by the University of Georgia. P.L. is supported by a predoctoral fellowship from the American Heart Association.

\section{REFERENCES}

Adoutte A, Claisse M, Maunoury R, Beisson J. 1985. Tubulin evolution: Ciliate-specific epitopes are conserved in the ciliary tubulin in metazoa. J Mol Evol 22: 220-229.

Adoutte A, Delgado P, Fleury A, Levilliers N, Lainé MC, Marty MC, Boisvieux-Ulrich E, Sandoz D. 1991. Microtubule diversity in ciliated cells: Evidence for its generation by post-translational modification in the axonemes of Paramecium and quail oviduct cells. Biol Cell 71: 227245.

Akella JS, Wloga D, Kim J, Starostina NG, Lyons-Abbott S, Morrissette NS, Dougan ST, Kipreos ET, Gaertig J. 2010. MEC-17 is an $\alpha$-tubulin acetyltransferase. Nature 467: $218-222$.

Alford LM, Stoddard D, Li JH, Hunter EL, Tritschler D, Bower R, Nicastro D, Porter ME, Sale WS. 2016. The nexin link and B-tubule glutamylation maintain the alignment of outer doublets in the ciliary axoneme. $\mathrm{Cy}$ toskeleton (Hoboken) 73: 331-340.

Alonso VL, Villanova GV, Ritagliati C, Machado Motta MC, Cribb P, Serra EC. 2014. Trypanosoma cruzi bromodomain factor 3 binds acetylated $\alpha$-tubulin and concentrates in the flagellum during metacyclogenesis. Eukaryot Cell 13: 822-831.

Alper JD, Decker F, Agana B, Howard J. 2014. The motility of axonemal dynein is regulated by the tubulin code. Biophys J 107: 2872-2880.

Arce CA, Barra HS. 1983. Association of tubulinyl-tyrosine carboxypeptidase with microtubules. FEBS Lett 157: $75-$ 78.

Backer CB, Gutzman JH, Pearson CG, Cheeseman IM. 2012. CSAP localizes to polyglutamylated microtubules and promotes proper cilia function and zebrafish development. Mol Biol Cell 23: 2122-2130.

Bangs FK, Schrode N, Hadjantonakis AK, Anderson KV. 2015. Lineage specificity of primary cilia in the mouse embryo. Nat Cell Biol 17: 113-122.

Barber CF, Heuser T, Carbajal-Gonzalez BI, Botchkarev VV Jr, Nicastro D. 2012. Three-dimensional structure of the radial spokes reveals heterogeneity and interactions with dyneins in Chlamydomonas flagella. Mol Biol Cell 23: 111-120.

Bosch Grau M, Gonzalez Curto G, Rocha C, Magiera MM, Marques Sousa P, Giordano T, Spassky N, Janke C. 2013.
Tubulin glycylases and glutamylases have distinct functions in stabilization and motility of ependymal cilia. $J$ Cell Biol 202: 441-451.

Bré MH, Redeker V, Quibell M, Darmanaden-Delome J, Bressac C, Cosson J, Huitore P, Schmitte JM, Rossier J, Johnson T, et al. 1996. Axonemal tubulin polyglycylation probed with two monoclonal antibodies: Widespread evolutionary distribution, appearance during spermatozoan maturation and possible function in motility. J Cell Sci 109: 727-738.

Bré MH, Redeker V, Vinh J, Rossier J, Levilliers N. 1998. Tubulin polyglycylation: Differential posttranslational modification of dynamic cytoplasmic and stable axonemal microtubules in Paramecium. Mol Biol Cell 9: 26552665.

Bui KH, Sakakibara H, Movassagh T, Oiwa K, Ishikawa T. 2009. Asymmetry of inner dynein arms and inter-doublet links in Chlamydomonas flagella. J Cell Biol 186: 437446.

Campbell PK, Waymire KG, Heier RL, Sharer C, Day DE, Reimann H, Jaje JM, Friedrich GA, Burmeister M, Bartness TJ, et al. 2002. Mutation of a novel gene results in abnormal development of spermatid flagella, loss of intermale aggression and reduced body fat in mice. Genetics 162: 307-320.

Chalfie M, Au M. 1989. Genetic control of differentiation of the Caenorhabditis elegans touch receptor neurons. Science 243: 1027-1033.

Choudhary C, Kumar C, Gnad F, Nielsen ML, Rehman M, Walther TC, Olsen JV, Mann M. 2009. Lysine acetylation targets protein complexes and co-regulates major cellular functions. Science 325: 834-840.

Chu CW, Hou F, Zhang J, Phu L, Loktev AV, Kirkpatrick DS, Jackson PK, Zhao Y, Zou H. 2011. A novel acetylation of $\beta$-tubulin by San modulates microtubule polymerization via down-regulating tubulin incorporation. Mol Biol Cell 22: $448-456$.

Cueva JG, Hsin J, Huang KC, Goodman MB. 2012. Posttranslational acetylation of $\alpha$-tubulin constrains protofilament number in native microtubules. Curr Biol 22: 1066-1074.

Dave D, Wloga D, Sharma N, Gaertig J. 2009. DYF-1 Is required for assembly of the axoneme in Tetrahymena thermophila. Eukaryot Cell 8: 1397-1406.

Davenport AM, Collins LN, Chiu H, Minor PJ, Sternberg PW, Hoelz A. 2014. Structural and functional characterization of the $\alpha$-tubulin acetyltransferase MEC-17. J Mol Biol 426: 2605-2616.

Duan J, Gorovsky MA. 2002. Both carboxy terminal tails of $\alpha$ and $\beta$ tubulin are essential, but either one will suffice. Curr Biol 12: 313-316.

Dymek EE, Smith EF. 2012. PF19 encodes the p60 catalytic subunit of katanin and is required for assembly of the flagellar central apparatus in Chlamydomonas. J Cell Sci 125: 3357-3366.

Dymek EE, Lefebvre PA, Smith EF. 2004. PF15p is the Chlamydomonas homologue of the katanin p80 subunit and is required for assembly of flagellar central microtubules. Eukaryot Cell 3: 870-879.

Eddé B, Rossier J, Le Caer JP, Desbruyères E, Gros F, Denoulet P. 1990. Posttranslational glutamylation of $\alpha$-tubulin. Science 247: 83-85. 
Erck C, Peris L, Andrieux A, Meissirel C, Gruber AD, Vernet M, Schweitzer A, Saoudi Y, Pointu H, Bosc C, et al. 2005. A vital role of tubulin-tyrosine-ligase for neuronal organization. Proc Natl Acad Sci 102: 7853-7858.

Ersfeld K, Wehland J, Plessmann U, Dodemont H, Gerke V, Weber K. 1993. Characterization of the tubulin-tyrosine ligase. J Cell Biol 120: 725-732.

Fernandez-Gonzalez A, La Spada AR, Treadaway J, Higdon JC, Harris BS, Sidman RL, Morgan JI, Zuo J. 2002. Purkinje cell degeneration $(p c d)$ phenotypes caused by mutations in the axotomy-induced gene, Nnal. Science 295: 1904-1906.

Friedmann DR, Aguilar A, Fan J, Nachury MV, Marmorstein R. 2012. Structure of the $\alpha$-tubulin acetyltransferase, $\alpha$ TAT1, and implications for tubulin-specific acetylation. Proc Natl Acad Sci 109: 19655-19660.

Fukushige T, Siddiqui ZK, Chou M, Culotti JG, Gogonea CB, Siddiqui SS, Hamelin M. 1999. MEC-12, an $\alpha$-tubulin required for touch sensitivity in C. elegans. J Cell Sci 112: 395-403.

Gaertig J, Cruz MA, Bowen J, Gu L, Pennock DG, Gorovsky MA. 1995. Acetylation of lysine 40 in $\alpha$-tubulin is not essential in Tetrahymena thermophila. J Cell Biol 129: $1301-1310$.

Garnham CP, Vemu A, Wilson-Kubalek EM, Yu I, Szyk A, Lander GC, Milligan RA, Roll-Mecak A. 2015. Multivalent microtubule recognition by tubulin tyrosine ligaselike family glutamylases. Cell 161: 1112-1123.

Greer CA, Shepherd GM. 1982. Mitral cell degeneration and sensory function in the neurological mutant mouse Purkinje cell degeneration (PCD). Brain Res 235: 156-161.

Hou Y, Qin H, Follit JA, Pazour GJ, Rosenbaum JL, Witman GB. 2007. Functional analysis of an individual IFT protein: IFT46 is required for transport of outer dynein arms into flagella. J Cell Biol 176: 653-665.

Howes SC, Alushin GM, Shida T, Nachury MV, Nogales E. 2014. Effects of tubulin acetylation and tubulin acetyltransferase binding on microtubule structure. Mol Biol Cell 25: 257-266.

Hoyle HD, Turner FR, Raff EC. 2008. Axoneme-dependent tubulin modifications in singlet microtubules of the Drosophila sperm tail. Cell Motil Cytoskeleton 65: 295-313.

Huang B, Piperno G, Luck DJ. 1979. Paralyzed flagella mutants of Chlamydomonas reinhardtii. Defective for axonemal doublet microtubule arms. J Biol Chem 254: $3091-$ 3099.

Huang K, Diener DR, Rosenbaum JL. 2009. The ubiquitin conjugation system is involved in the disassembly of cilia and flagella. J Cell Biol 186: 601-613.

Hubbert C, Guardiola A, Shao R, Kawaguchi Y, Ito A, Yoshida M, Wang XF, Yao T-P. 2003. Identification of HDAC6 as a microtubule-associated deacetylase. Nature 417: 455-458.

Ikegami K, Setou M. 2009. TTLL10 can perform tubulin glycylation when co-expressed with TTLL8. FEBS Lett 583: $1957-1963$

Ikegami K, Horigome D, Mukai M, Livnat I, Macgregor GR, Setou M. 2008. TTLL10 is a protein polyglycylase that can modify nucleosome assembly protein 1 . FEBS Lett $\mathbf{5 8 2}$ : $1129-1134$.
Ikegami K, Sato S, Nakamura K, Ostrowski LE, Setou M. 2010. Tubulin polyglutamylation is essential for airway ciliary function through the regulation of beating asymmetry. Proc Natl Acad Sci 107: 10490-10495.

Ishikawa T. 2015. Cryo-electron tomography of motile cilia and flagella. Cilia 4: 3.

Janke C. 2014. The tubulin code: Molecular components, readout mechanisms, and functions. J Cell Biol 206: 461472.

Janke C, Rogowski K, Wloga D, Regnard C, Kajava AV, Strub JM, Temurak N, van Dijk J, Boucher D, van Dorsselaer A, et al. 2005. Tubulin polyglutamylase enzymes are members of the TTL domain protein family. Science 308: $1758-1762$.

Jerka-Dziadosz M, Jenkins LM, Nelsen EM, Williams NE, Jaeckel-Williams R, Frankel J. 1995. Cellular polarity in ciliates: Persistence of global polarity in a disorganized mutant of Tetrahymena thermophila that disrupts cytoskeletal organization. Dev Biol 169: 644-661.

Johnson KA. 1998. The axonemal microtubules of the Chlamydomonas flagellum differ in tubulin isoform content. $J$ Cell Sci 111: 313-320.

Kalebic N, Martinez C, Perlas E, Hublitz P, Bilbao-Cortes D, Fiedorczuk K, Andolfo A, Heppenstall PA. 2013a. Tubulin acetyltransferase $\alpha$ TAT1 destabilizes microtubules independently of its acetylation activity. Mol Cell Biol 33: 1114-1123.

Kalebic N, Sorrentino S, Perlas E, Bolasco G, Martinez C, Heppenstall PA. 2013b. $\alpha$ TAT1 is the major $\alpha$-tubulin acetyltransferase in mice. Nat Commun 4: 1962.

Kamiya R. 2002. Functional diversity of axonemal dyneins as studied in Chlamydomonas mutants. Int Rev Cytol 219: $115-155$.

Kann ML, Prigent Y, Levilliers N, Bré MH, Fouquet JP. 1998. Expression of glycylated tubulin during the differentiation of spermatozoa in mammals. Cell Motil Cytoskeleton 41: $341-352$.

Kaul N, Soppina V, Verhey KJ. 2014. Effects of $\alpha$-tubulin K40 acetylation and detyrosination on kinesin-1 motility in a purified system. Biophys J 106: 2636-2643.

Kim J, Lee JE, Heynen-Genel S, Suyama E, Ono K, Lee K, Ideker T, Aza-Blanc P, Gleeson JG. 2010. Functional genomic screen for modulators of ciliogenesis and cilium length. Nature 464: 1048-1051.

Kim GW, Li L, Gorbani M, You L, Yang XJ. 2013. Mice lacking $\alpha$-tubulin acetyltransferase 1 are viable but display $\alpha$-tubulin acetylation deficiency and dentate gyrus distortion. J Biol Chem 288: 20334-20350.

Kimura Y, Kurabe N, Ikegami K, Tsutsumi K, Konishi Y, Kaplan OI, Kunitomo H, Iino Y, Blacque OE, Setou M. 2010. Identification of tubulin deglutamylase among Caenorhabditis elegans and mammalian cytosolic carboxypeptidases (CCPs). J Biol Chem 285: 22936-22941.

Konno A, Ikegami K, Konishi Y, Yang HJ, Abe M, Yamazaki M, Sakimura K, Yao I, Shiba K, Inaba K, et al. 2016. Doublet 7 shortening, doublet 5-preferential poly-Glu reduction, and beating stall of sperm flagella in Ttll19-/- mice. J Cell Sci 129: 2757-2766.

Kormendi V, Szyk A, Piszczek G, Roll-Mecak A. 2012. Crystal structures of tubulin acetyltransferase reveal a con- 
D. Wloga et al.

served catalytic core and the plasticity of the essential $\mathrm{N}$ terminus. J Biol Chem 287: 41569-41575.

Kotani N, Sakakibara H, Burgess SA, Kojima H, Oiwa K. 2007. Mechanical properties of inner-arm dynein- $\mathrm{f}(\mathrm{dy}-$ nein I1) studied with in vitro motility assays. Biophys J 93: 886-894.

Kozminski KG, Diener DR, Rosenbaum JL. 1993. High level expression of nonacetylatable $\alpha$-tubulin in Chlamydomonas reinhardtii. Cell Motil Cytoskel 25: 158-170.

Kozminski KG, Beech PL, Rosenbaum JL. 1995. The Chlamydomonas kinesin-like protein FLA10 is involved in motility associated with the flagellar membrane. $J$ Cell Biol 131: 1517-1527.

Kubo T, Yanagisawa HA, Yagi T, Hirono M, Kamiya R. 2010. Tubulin polyglutamylation regulates axonemal motility by modulating activities of inner-arm dyneins. Curr Biol 20: $441-445$.

Kubo T, Yagi T, Kamiya R. 2012. Tubulin polyglutamylation regulates flagellar motility by controlling a specific innerarm dynein that interacts with the dynein regulatory complex. Cytoskeleton (Hoboken) 69: 1059-1068.

Kubo T, Yanagisawa HA, Liu Z, Shibuya R, Hirono M, Kamiya R. 2014. A conserved flagella-associated protein in Chlamydomonas, FAP234, is essential for axonemal localization of tubulin polyglutamylase TTLL9. Mol Biol Cell 25: 107-117.

Kubo T, Hirono M, Aikawa T, Kamiya R, Witman GB. 2015. Reduced tubulin polyglutamylation suppresses flagellar shortness in Chlamydomonas. Mol Biol Cell 26: 2810 2822.

Kumar N, Flavin M. 1981. Preferential action of a brain detyrosinolating carboxypeptidase on polymerized tubulin. J Biol Chem 256: 7678-7680.

Lacroix B, van Dijk J, Gold ND, Guizetti J, Aldrian-Herrada G, Rogowski K, Gerlich DW, Janke C. 2010. Tubulin polyglutamylation stimulates spastin-mediated microtubule severing. J Cell Biol 189: 945-954.

Lechtreck KF, Geimer S. 2000. Distribution of polyglutamylated tubulin in the flagellar apparatus of green flagellates. Cell Motil Cytoskeleton 47: 219-235.

LeDizet M, Piperno G. 1987. Identification of an acetylation site of Chlamydomonas $\alpha$-tubulin. Proc Natl Acad Sci 84: 5720-5724.

LeDizet M, Piperno G. 1995. The light chain p28 associates with a subset of inner dynein arm heavy chains in Chlamydomonas axonemes. Mol Biol Cell 6: 697-711.

Lee JE, Silhavy JL, Zaki MS, Schroth J, Bielas SL, Marsh SE, Olvera J, Brancati F, Iannicelli M, Ikegami K, et al. 2012. CEP41 is mutated in Joubert syndrome and is required for tubulin glutamylation at the cilium. Nat Genet 44: 193-199.

Lee GS, He Y, Dougherty EJ, Jimenez-Movilla M, Avella M, Grullon S, Sharlin DS, Guo C, Blackford JA Jr, Awasthi S, et al. 2013. Disruption of Ttll5/Stamp gene (tubulin tyrosine ligase-like protein 5/SRC-1 and TIF2-associated modulatory protein gene) in male mice causes sperm malformation and infertility. J Biol Chem 288: $15167-$ 15180 .

L'Hernault SW, Rosenbaum JL. 1983. Chlamydomonas $\alpha$ tubulin is posttranslationally modified in the flagella during flagellar assembly. J Cell Biol 97: 258-263.
Li W, Zhong C, Li L, Sun B, Wang W, Xu S, Zhang T, Wang C, Bao L, Ding J. 2012. Molecular basis of the acetyltransferase activity of MEC-17 towards $\alpha$-tubulin. Cell Res 22: 1707-1711.

Liang Y, Meng D, Zhu B, Pan J. 2016. Mechanism of ciliary disassembly. Cell Mol Life Sci 73: 1787-1802.

Liu N, Xiong Y, Li S, Ren Y, He Q, Gao S, Zhou J, Shui W. 2015. New HDAC6-mediated deacetylation sites of tubulin in the mouse brain identified by quantitative mass spectrometry. Sci Rep 5: 16869.

Lu C, Srayko M, Mains PE. 2004. The Caenorhabditis elegans microtubule-severing complex MEI-1/MEI-2 katanin interacts differently with two superficially redundant $\beta$-tubulin isotypes. Mol Biol Cell 15: 142-150.

Magiera MM, Janke C. 2013. Investigating tubulin posttranslational modifications with specific antibodies. Methods Cell Biol 115: 247-267.

Million K, Larcher J-C, Laokili J, Bourguigon D, Marano F, Tournier F. 1999. Polyglutamylation and polyglycylation of $\alpha$ - and $\beta$-tubulins during in vitro ciliated cell differentiation of human respiratory epithelial cells.

Mukai M, Ikegami K, Sugiura Y, Takeshita K, Nakagawa A, Setou M. 2009. Recombinant mammalian tubulin polyglutamylase TTLL7 performs both initiation and elongation of polyglutamylation on $\beta$-tubulin through a random sequential pathway. Biochemistry 48: 1084-1093.

Nicastro D, Fu X, Heuser T, Tso A, Porter ME, Linck RW. 2011. Cryo-electron tomography reveals conserved features of doublet microtubules in flagella. Proc Natl Acad Sci 108: E845-853.

Nogales E, Whittaker M, Milligan RA, Downing KH. 1999. High-resolution model of the microtubule. Cell 96: 7988.

North BJ, Marshall BL, Borra MT, Denu JM, Verdin E. 2003. The human Sir2 ortholog, SIRT2, is an $\mathrm{NAD}^{+}$-dependent tubulin deacetylase. Mol Cell 11: 437-444.

O’Hagan R, Barr MM. 2012. Regulation of tubulin glutamylation plays cell-specific roles in the function and stability of sensory cilia. Worm 1: 155-159.

O’Hagan R, Piasecki BP, Silva M, Phirke P, Nguyen KC, Hall DH, Swoboda P, Barr MM. 2011. The tubulin deglutamylase CCPP-1 regulates the function and stability of sensory cilia in C. elegans. Curr Biol 21: 1685-1694.

Ohta S, Hamada M, Sato N, Toramoto I. 2015. Polyglutamylated tubulin binding protein C1orf96/CSAP is involved in microtubule stabilization in mitotic spindles. PLoS ONE 10: e0142798.

Pathak N, Austin CA, Drummond IA. 2011. Tubulin tyrosine ligase-like genes $t$ tll 3 and ttll6 maintain zebrafish cilia structure and motility. J Biol Chem 286: $11685-$ 11695.

Pathak N, Austin-Tse CA, Liu Y, Vasilyev A, Drummond IA. 2014. Cytoplasmic carboxypeptidase 5 regulates tubulin glutamylation and zebrafish cilia formation and function. Mol Biol Cell 25: 1836-1844.

Paturie-Lafanechère L, Manier M, Trigault N, Pirollet F, Mazarguil H, Job D. 1994. Accumulation of $\delta$-2-tubulin, a major tubulin variant that cannot be tyrosinated, in neuronal tissues and in stable microtubule assemblies. $J$ Cell Sci 107: 1529-1543. 
Pigino G, Cantele F, Vannuccini E, Lanzavecchia S, Paccagnini E, Lupetti P. 2009. Electron-tomographic analysis of intraflagellar transport particle trains in situ. J Cell Biol 187: $135-148$.

Piperno G, Fuller MT. 1985. Monoclonal antibodies specific for an acetylated form of $\alpha$-tubulin recognize the antigen in cilia and flagella from a variety of organisms. J Cell Biol 101: 2085-2094.

Prota AE, Magiera MM, Kuijpers M, Bargsten K, Frey D, Wieser M, Jaussi R, Hoogenraad CC, Kammerer RA, Janke C, et al. 2013. Structural basis of tubulin tyrosination by tubulin tyrosine ligase. J Cell Biol 200: 259-270.

Pugacheva EN, Jablonski SA, Hartman TR, Henske EP, Golemis EA. 2007. HEF1-dependent Aurora A activation induces disassembly of the primary cilium. Cell 129: 1351-1363.

Raff EC, Hoyle HD, Popodi EM, Turner FR. 2008. Axoneme $\beta$-tubulin sequence determines attachment of outer dynein arms. Curr Biol 18: 911-914.

Ran J, Yang Y, Li D, Liu M, Zhou J. 2015. Deacetylation of $\alpha$ tubulin and cortactin is required for HDAC6 to trigger ciliary disassembly. Sci Rep 5: 12917.

Redeker V, Le Caer JP, Rossier J, Promé JC. 1991. Structure of the polyglutamyl side chain posttranslationally added to $\alpha$-tubulin. J Biol Chem 266: 23461-23466.

Redeker V, Melki R, Promé D, Le Caer JP, Rossier J. 1992. Structure of tubulin C-terminal domain obtained by subtilisin treatment. The major $\alpha$ - and $\beta$-tubulin isotypes from pig brain are glutamylated. FEBS Lett 313: 185-192.

Redeker V, Levilliers N, Schmitter JM, Le Caer JP, Rossier J, Adoutte A, Bré MH. 1994. Polyglycylation of tubulin: A post-translational modification in axonemal microtubules. Science 266: 1688-1691.

Reed NA, Cai D, Blasius L, Jih GT, Meyhofer E, Gaertig J, Verhey KJ. 2006. Microtubule acetylation promotes kinesin-1 binding and transport. Curr Biol 16: 2166-2172.

Regnard C, Fesquet D, Janke C, Boucher D, Desbruyères E, Koulakoff A, Insina C, Travo P, Edde B. 2003. Characterization of PGs1, a subunit of a protein complex co-purifying with tubulin polyglutamylase. J Cell Sci 116: 41814190.

Rocha C, Papon L, Cacheux W, Marques Sousa P, Lascano V, Tort O, Giordano T, Vacher S, Lemmers B, Mariani P, et al. 2014. Tubulin glycylases are required for primary cilia, control of cell proliferation and tumor development in colon. EMBO J 33: 2247-2260.

Rogowski K, Juge F, van Dijk J, Wloga D, Strub JM, Levilliers N, Thomas D, Bre MH, Van Dorsselaer A, Gaertig J, et al. 2009. Evolutionary divergence of enzymatic mechanisms for posttranslational polyglycylation. Cell 137: 10761087.

Rogowski K, van Dijk J, Magiera MM, Bosc C, Deloulme JC, Bosson A, Peris L, Gold ND, Lacroix B, Grau MB, et al. 2010. A family of protein-deglutamylating enzymes associated with neurodegeneration. Cell 143: 564-578.

Roll-Mecak A. 2015. Intrinsically disordered tubulin tails: Complex tuners of microtubule functions? Semin Cell Dev Biol 37: 11-19.

Roll-Mecak A, Vale RD. 2008. Structural basis of microtubule severing by the hereditary spastic paraplegia protein spastin. Nature 451: 363-367.
Satish Tammana TV, Tammana D, Diener DR, Rosenbaum J. 2013. Centrosomal protein CEP104 (Chlamydomonas FAP256) moves to the ciliary tip during ciliary assembly. J Cell Sci 126: 5018-5029.

Schroder HC, Wehland J, Weber K. 1985. Purification of brain tubulin-tyrosine ligase by biochemical and immunological methods. J Cell Biol 100: 276-281.

Sergouniotis PI, Chakarova C, Murphy C, Becker M, Lenassi E, Arno G, Lek M, MacArthur DG, Consortium UCE, Bhattacharya SS, et al. 2014. Biallelic variants in TTLL5, encoding a tubulin glutamylase, cause retinal dystrophy. Am J Hum Genet 94: 760-769.

Shang Y, Li B, Gorovsky MA. 2002. Tetrahymena thermophila contains a conventional $\gamma$ tubulin that is differentially required for the maintenance of different microtubule organizing centers. J Cell Biol 158: 1195-1206.

Sharma N, Bryant J, Wloga D, Donaldson R, Davis RC, Jerka-Dziadosz M, Gaertig J. 2007. Katanin regulates dynamics of microtubules and biogenesis of motile cilia. $J$ Cell Biol 178: 1065-1079.

Shida T, Cueva JG, Xu Z, Goodman MB, Nachury MV. 2010. The major $\alpha$-tubulin K40 acetyltransferase $\alpha$ TAT1 promotes rapid ciliogenesis and efficient mechanosensation. Proc Natl Acad Sci 107: 21517-21522.

Sirajuddin M, Rice LM, Vale RD. 2014. Regulation of microtubule motors by tubulin isotypes and post-translational modifications. Nat Cell Biol 16: 335-344.

Song Y, Brady ST. 2015. Post-translational modifications of tubulin: Pathways to functional diversity of microtubules. Trends Cell Biol 25: 125-136.

Soppina V, Herbstman JF, Skiniotis G, Verhey KJ. 2012. Luminal localization of $\alpha$-tubulin K40 acetylation by cryoEM analysis of fab-labeled microtubules. PLoS ONE 7: e48204.

Stepanek L, Pigino G. 2016. Microtubule doublets are double-track railways for intraflagellar transport trains. Science 352: 721-724.

Sun X, Park JH, Gumerson J, Wu Z, Swaroop A, Qian H, Roll-Mecak A, Li T. 2016. Loss of RPGR glutamylation underlies the pathogenic mechanism of retinal dystrophy caused by TTLL5 mutations. Proc Natl Acad Sci 113: E2925-E2934.

Suryavanshi S, Edde B, Fox LA, Guerrero S, Hard R, Hennessey T, Kabi A, Malison D, Pennock D, Sale WS, et al. 2010. Tubulin glutamylation regulates ciliary motility by altering inner dynein arm activity. Curr Biol 20: 435-440.

Szyk A, Deaconescu A, Piszczek G, Roll-Mecak A. 2011. Tubulin tyrosine ligase structure reveals adaptation of an ancient fold to bind and modify tubulin. Nat Struct Mol Biol 18: 1250-1258.

Szyk A, Deaconescu AM, Spector J, Goodman B, Valenstein ML, Ziolkowska NE, Kormendi V, Grigorieff N, Roll-Mecak A. 2014. Molecular basis for age-dependent microtubule acetylation by tubulin acetyltransferase. Cell 157: 1405-1415.

Taschner M, Vetter M, Lorentzen E. 2012. Atomic resolution structure of human $\alpha$-tubulin acetyltransferase bound to acetyl-CoA. Proc Natl Acad Sci 109: 19649-19654.

Thazhath R, Liu C, Gaertig J. 2002. Polyglycylation domain of $\beta$-tubulin maintains axonemal architecture and affects cytokinesis in Tetrahymena. Nat Cell Biol 4: 256-259. 
D. Wloga et al.

Topalidou I, Keller C, Kalebic N, Nguyen KC, Somhegyi H, Politi KA, Heppenstall P, Hall DH, Chalfie M. 2012. Enzymatic and non-enzymatic activities of the tubulin acetyltransferase MEC-17 are required for microtubule organization and mechanosensation in C. elegans. Curr Biol 22: 1057-1065.

Tort O, Tanco S, Rocha C, Bieche I, Seixas C, Bosc C, Andrieux A, Moutin MJ, Aviles FX, Lorenzo J, et al. 2014. The cytosolic carboxypeptidases CCP2 and CCP3 catalyze posttranslational removal of acidic amino acids. $\mathrm{Mol}$ Biol Cell 25: 3017-3027.

Valenstein ML, Roll-Mecak A. 2016. Graded control of microtubule severing by tubulin glutamylation. Cell 164: 911-921.

van Dijk J, Rogowski K, Miro J, Lacroix B, Eddé B, Janke C. 2007. A targeted multienzyme mechanism for selective microtubule polyglutamylation. Mol Cell 26: 437-448.

van Dijk J, Miro J, Strub JM, Lacroix B, van Dorsselaer A, Edde B, Janke C. 2008. Polyglutamylation is a post-translational modification with a broad range of substrates. $J$ Biol Chem 283: 3915-3922.

Varberg JM, Padgett LR, Arrizabalaga G, Sullivan WJ. 2016. TgATAT-mediated $\alpha$-tubulin acetylation is required for division of the protozoan parasite Toxoplasma gondii. mSphere 1: e00088-e00015.

Verhey KJ, Gaertig J. 2007. The tubulin code. Cell Cycle 6: 2152-2160.

Vogel P, Hansen G, Fontenot G, Read R. 2010. Tubulin tyrosine ligase-like 1 deficiency results in chronic rhinosinusitis and abnormal development of spermatid flagella in mice. Vet Pathol 47: 703-712.

Walter WJ, Beranek V, Fischermeier E, Diez S. 2012. Tubulin acetylation alone does not affect kinesin-1 velocity and run length in vitro. PLoS ONE 7: e42218.

Wloga D, Rogowski K, Sharma N, Van Dijk J, Janke C, Edde B, Bre MH, Levilliers N, Redeker V, Duan J, et al. 2008. Glutamylation on $\alpha$-tubulin is not essential but affects the assembly and functions of a subset of microtubules in Tetrahymena thermophila. Eukaryot Cell 7: 1362-1372.

Wloga D, Webster DM, Rogowski K, Bre MH, Levilliers N, Jerka-Dziadosz M, Janke C, Dougan ST, Gaertig J. 2009. TTLL3 is a tubulin glycine ligase that regulates the assembly of cilia. Dev Cell 16: 867-876.

Wloga D, Dave D, Meagley J, Rogowski K, Jerka-Dziadosz M, Gaertig J. 2010. Hyperglutamylation of tubulin can either stabilize or destabilize microtubules in the same cell. Eukaryot Cell 9: 184-193.

Xia L, Hai B, Gao Y, Burnette D, Thazhath R, Duan J, Bré MH, Levilliers N, Gorovsky MA, Gaertig J. 2000. Poly- glycylation of tubulin is essential and affects cell motility and division in Tetrahymena thermophila. J Cell Biol 149: 1097-1106.

Xia P, Ye B, Wang S, Zhu X, Du Y, Xiong Z, Tian Y, Fan Z. 2016. Glutamylation of the DNA sensor cGAS regulates its binding and synthase activity in antiviral immunity. Nat Immunol 17: 369-378.

Yamamoto R, Hirono M, Kamiya R. 2010. Discrete PIH proteins function in the cytoplasmic preassembly of different subsets of axonemal dyneins. J Cell Biol 190: 6571.

Yanagisawa HA, Mathis G, Oda T, Hirono M, Richey EA, Ishikawa H, Marshall WF, Kikkawa M, Qin H. 2014. FAP20 is an inner junction protein of doublet microtubules essential for both the planar asymmetrical waveform and stability of flagella in Chlamydomonas. Mol Biol Cell 25: 1472-1483.

Yang Y, Ran J, Liu M, Li D, Li Y, Shi X, Meng D, Pan J, Ou G, Aneja R, et al. 2014. CYLD mediates ciliogenesis in multiple organs by deubiquitinating Cep70 and inactivating HDAC6. Cell Res 24: 1342-1353.

Ye B, Li C, Yang Z, Wang Y, Hao J, Wang L, Li Y, Du Y, Hao L, Liu B, et al. 2014. Cytosolic carboxypeptidase CCP6 is required for megakaryopoiesis by modulating Mad2 polyglutamylation. J Exp Med 211: 2439-2454.

Yu I, Garnham CP, Roll-Mecak A. 2015. Writing and reading the tubulin code. J Biol Chem 290: 17163-17172.

Yuzawa S, Kamakura S, Hayase J, Sumimoto H. 2015. Structural basis of cofactor-mediated stabilization and substrate recognition of the $\alpha$-tubulin acetyltransferase $\alpha$ TAT1. Biochem J 467: 103-113.

Zhang Y, Ma C, Delohery T, Nasipak B, Foat BC, Bounoutas A, Bussemaker HJ, Kim SK, Chalfie M. 2002. Identification of genes expressed in C. elegans touch receptor neurons. Nature 418: 331-335.

Zhang Y, Li N, Caron C, Matthias G, Hess D, Khochbin S, Matthias P. 2003. HDAC-6 interacts with and deacetylates tubulin and microtubules in vivo. EMBO J 22: $1168-$ 1179.

Zhang Y, Kwon S, Yamaguchi T, Cubizolles F, Rousseaux S, Kneissel M, Cao C, Li N, Cheng HL, Chua K, et al. 2008. Mice lacking histone deacetylase 6 have hyperacetylated tubulin but are viable and develop normally. Mol Cell Biol 28: $1688-1701$.

Zhou X, Fan LX, Li K, Ramchandran R, Calvet JP, Li X. 2014. SIRT2 regulates ciliogenesis and contributes to abnormal centrosome amplification caused by loss of polycystin-1. Hum Mol Genet 23: 1644-1655. 


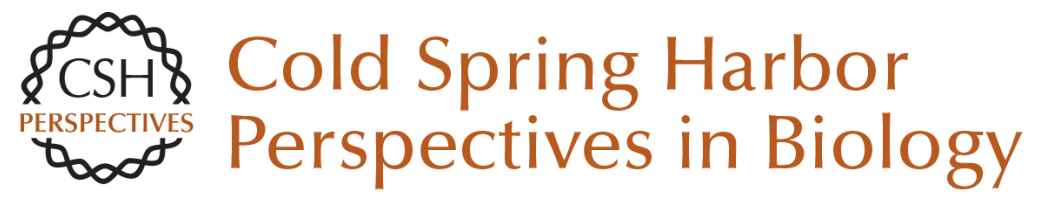

\section{Posttranslational Modifications of Tubulin and Cilia}

Dorota Wloga, Ewa Joachimiak, Panagiota Louka and Jacek Gaertig

Cold Spring Harb Perspect Biol 2017; doi: 10.1101/cshperspect.a028159 originally published online December 21, 2016

\section{Subject Collection Cilia}

Ciliary Mechanisms of Cyst Formation in

Polycystic Kidney Disease

Ming Ma, Anna-Rachel Gallagher and Stefan Somlo

Photoreceptor Cilia and Retinal Ciliopathies Kinga M. Bujakowska, Qin Liu and Eric A. Pierce

G-Protein-Coupled Receptor Signaling in Cilia Kirk Mykytyn and Candice Askwith

Evolution of Cilia David R. Mitchell

Transition Zone Migration: A Mechanism for Cytoplasmic Ciliogenesis and Postaxonemal Centriole Elongation

Tomer Avidor-Reiss, Andrew Ha and Marcus L. Basiri

Cilia and Obesity

Christian Vaisse, Jeremy F. Reiter and Nicolas F. Berbari

Posttranslational Modifications of Tubulin and Cilia

Dorota Wloga, Ewa Joachimiak, Panagiota Louka, et al.
Cilia in Left-Right Symmetry Breaking Kyosuke Shinohara and Hiroshi Hamada

Discovery, Diagnosis, and Etiology of Craniofacial Ciliopathies

Elizabeth N. Schock and Samantha A. Brugmann

Axoneme Structure from Motile Cilia Takashi Ishikawa

Cilia and Ciliopathies in Congenital Heart Disease Nikolai T. Klena, Brian C. Gibbs and Cecilia W. Lo

Sperm Sensory Signaling Dagmar Wachten, Jan F. Jikeli and U. Benjamin Kaupp

Primary Cilia and Coordination of Receptor Tyrosine Kinase (RTK) and Transforming Growth Factor $\beta$ (TGF- $\beta$ ) Signaling Søren T. Christensen, Stine K. Morthorst, Johanne B. Mogensen, et al.

Primary Cilia and Mammalian Hedgehog Signaling Fiona Bangs and Kathryn V. Anderson

For additional articles in this collection, see http://cshperspectives.cshlp.org/cgi/collection/

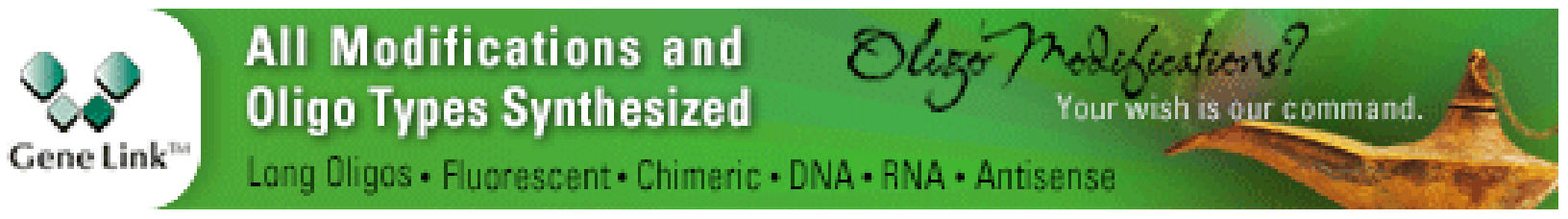

Copyright @ 2017 Cold Spring Harbor Laboratory Press; all rights reserved 
Radial Spokes--A Snapshot of the Motility Regulation, Assembly, and Evolution of Cilia and Flagella

Xiaoyan Zhu, Yi Liu and Pinfen Yang
Cilia and Mucociliary Clearance

Ximena M. Bustamante-Marin and Lawrence E. Ostrowski

For additional articles in this collection, see http://cshperspectives.cshlp.org/cgi/collection/

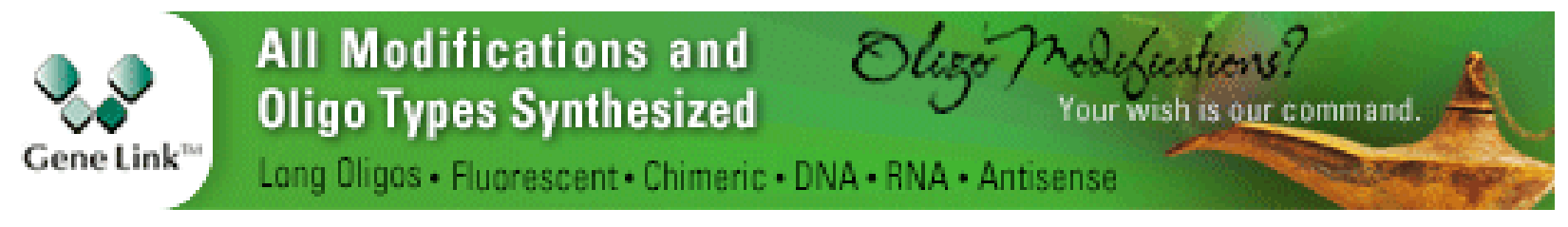

Copyright @ 2017 Cold Spring Harbor Laboratory Press; all rights reserved 